\title{
GEODETIC OBSERVATIONS OF THE OCEAN SURFACE TOPOGRAPHY, GEOID, CURRENTS, AND CHANGES IN OCEAN MASS AND VOLUME
}

C.K. Shum ${ }^{(1)}$, Hans-Peter Plag ${ }^{(2)}$, Jens Schröter ${ }^{(3)}$, Victor Zlotnicki ${ }^{(4)}$, Peter Bender ${ }^{(5)}$, Alexander Braun ${ }^{(6)}$, Anny Cazenave $^{(7)}$, Don Chamber ${ }^{(8)}$, Jianbin Duan ${ }^{(1)}$, William Emery ${ }^{(9)}$, Georgia Fotopoulos ${ }^{(6)}$,

Viktor Gouretski $^{(10)}$, Richard Gross ${ }^{(4)}$, Thomas Gruber ${ }^{(11)}$, Junyi Guo ${ }^{(1)}$, Guoqi Han ${ }^{(12)}$, Chris Hughes ${ }^{(13)}$, Masayoshi Ishii ${ }^{(14)}$, Steven Jayne ${ }^{(15)}$, Johnny Johannessen ${ }^{(16)}$, Per Knudsen ${ }^{(17)}$, Chung-Yen Kuo ${ }^{(18)}$, Eric Leuliette $^{(19)}$, Sydney Levitus (20), Nikolai Maximenko ${ }^{(21)}$, Laury Miller ${ }^{(19)}$, James Morison ${ }^{(22)}$,' Harunur Rashid $^{(23)}$, John Ries ${ }^{(24)}$, Markus Rothache ${ }^{(25)}$, Reiner Rummel ${ }^{(11)}$, Kazuo Shibuya ${ }^{(26)}$, Michael Sideris $^{(27)}$, Y. Tony Song ${ }^{(4)}$, Detlef Stammer ${ }^{(28)}$, Maik Thomas ${ }^{(29)}$, Josh Willis ${ }^{(4)}$, Philip Woodworth ${ }^{(13)}$

(1) Division of Geodetic Science, School of Earth Sciences, Ohio State University, 275 Mendenhall, 125 S. Oval Mall 43210 Columbus USA, Email: ckshum@osu.edu; duan.29@osu.edu; guo.81@osu.edu

${ }^{(2)}$ Nevada Bureau of Mines \& Geology \& Seismology Lab., University of Nevada, Mail Stop 178, 1664 N. Virginia Street, 89557 Reno Nevada 89557, USA, Email: hpplag@unr.edu

${ }^{(3)}$ Alfred-Wegener-Institute for Polar \& Marine Research, Postfach 120161, D-27515 Bremerhaven, Germany, Email: Jens.Schroeter@awi.de

(4) Jet Propulsion Laboratory, California Institute of Technology, 4800 Oak Grove Dr., Pasadena, CA 91109 USA, Email: Victor.Zlotnicki@jpl.nasa.gov; Tony.Song@jpl.nasa.gov; richard.gross@jpl.nasa.gov; joshua.k.willis@jpl.nasa.gov

${ }^{(5)}$ Joint Institute for Laboratory Astrophysics, University of Colorado \& NIST (National Institute of Standards and Technology), 440 University of Colorado, Boulder, CO 80309-5004 USA, Email: pbender@jila.colorado.edu

${ }^{(6)}$ Department of Geosciences, University of Texas at Dallas, FO 21, 800 West Campbell Road, Richardson, TX 75080-302 USA, Email: braun@utdallas.edu; foto@utdallas.edu

${ }^{(7)}$ LEGOS (Laboratoire d'Études en Géophysique et Océanographie), Centre National d'Études Spatiales, 18,av.Edouard Belin, 31401 Toulouse Cedex 9 France,Email: anny.cazenave@cnes.fr

${ }^{(8)}$ College of Marine Science, University of South Florida, 1407 th Ave S, St. Petersburg, FL 33701 USA, Email: dchambers@marine.usf.edu

(9) Colorado Center for Astrodynamics Research, University of Colorado, ECNT 320, 431 UCB, University of Colorado, Boulder, CO 80309-0431 USA, Email: emery@colorado.edu

${ }^{(10)}$ KlimaCampus Universität Hamburg, Bundesstr. 53, 20146 Hamburg, Germany, Email: viktor.gouretski@zmaw.de; detlef.stammer@zmaw.de

${ }^{(11)}$ Institute of Astronomy \& Physical Geodesy, Technische Universität Muenchen, Arcisstraße 21. D-80333 München. Germany,Email: thomas.gruber@bv.tum.de; rummel@bv.tu-muenchen.de

${ }^{(12)}$ Fisheries and Oceans Canada, Northwest Atlantic Fisheries Centre, P.O. Box 5667. St. John's NL A1C 5X1 Canada, Email: HanG@dfo-mpo.gc.ca

${ }^{(13)}$ Proudman Oceanographic Laboratory, 6 Brownlow St, Liverpool, Merseyside L3 5DA, United Kingdom, Email: cwh@pol.ac.uk; plw@pol.ac.uk

${ }^{(14)}$ Frontier Research Center for Global Change, 3173-25 Showamachi, Kanazawa-ku, Yokohama City, Kanagawa 236-0001, Japan, Email: ism@jamstec.go.jp

${ }^{(15)}$ Woods Hole Oceanographic Institution, 266 Woods Hole Road, Woods Hole, MA 02543, USA,

Email: sjayne@whoi.edu

${ }^{(16)}$ Nansen Environmental and Remote Sensing Centre, Thorm $\phi$ hlensgt. 47, N-5006 Bergen, Norway, Email: johnny.johannessen@nersc.no

${ }^{(17)}$ National Space Institute, Technical University of Denmark, Anker Engelunds Vej 1. Building 101A, 2nd Floor, 2800 Kgs. Lyngby, Denmark, Email: pk@space.dtu.dk

${ }^{(18)}$ Department of Geomatics, National Cheng Kung University, No. 1, University Road, Tainan 701, Taiwan, Email:kuo70@mail.ncku.edu.tw

(19) Laboratory for Satellite Altimetry, NOAA (National Oceanic and Atmospheric Administration), Silver Spring MD 20910-3282,USA, Email: Eric.Leuliette@noaa.gov; Laury.Miller@noaa.gov

${ }^{(20)}$ Ocean Climate Laboratory, National Ocean Data Center, NOAA (National Oceanic and Atmospheric

Administration), 1315 East-West Highway E/OC1 Silver Spring USA, Email: Sydney.Levitus@noaa.gov

${ }^{(21)}$ International Pacific Research Center, University of Hawaii, 1680 East West Road, Honolulu, Hawaii 96822, USA, Email: maximenk@hawaii.edu

${ }^{(22)}$ Polar Science Center, Applied Physics Lab., University of Washington, 1013 NE 40th St, Seattle, WA 98105-6698, USA, Email: morison@apl.washington.edu 
${ }^{(23)}$ Byrd Polar Research Center, Ohio State University, Enarson Hall 154 W 12th Avenue, Columbus, Ohio 43210 USA, Email: rashid.29@osu.edu

${ }^{(24)}$ Center for Space Research, University of Texas at Austin, 3925 West Braker Lane, Suite 200, Austin, Texas 78759-5321 USA, Email: ries@csr.utexas.edu

${ }^{(25)}$ Institute of Geodesy \& Photogrammetry, ETH (Eidgenössische Technische Hochschule) Zurich, HG F37/38/39/41/43, Rämistrasse 101, 8092 Zurich, Switzerland, Email: markus.rothacher@ethz.ch

${ }^{(26)}$ CAEM (Commission for Aeronautical Meteorology), National Institute of Polar Research, 10-3, Midoricho, Tachikawa, Tokyo 190-8518, Japan, Email: shibuya@nipr.ac.jp

${ }^{(27)}$ Department of Geomatics Engineering, University of Calgary, 2500 University Dr. NW, Calgary, Alberta T2N 1N4 Canada,Email: sideris@ucalgary.ca

${ }^{(28)}$ Center for Marine and Climate Research, KlimaCampus Universitat Hamburg, Bundesstr. 53, 20146 Hamburg, Germany, Email: detlef.stammer@zmaw.de

(29) GFZ (German Research Centre for Geosciences/GeoForschungsZentrum), Telegrafenberg, 14473 Potsdam, Germany, Email: maik.thomas@gfz-potsdam.de

\section{ABSTRACT}

The tools of geodesy have the potential to transform the Ocean Observing System. Geodetic observations are unique in the way that these methods produce accurate, quantitative, and integrated observations of gravity, ocean circulation, sea surface height, ocean bottom pressure, and mass exchanges among the ocean, cryosphere, and land. These observations have made fundamental contributions to the monitoring and understanding of physical ocean processes. In particular, geodesy is the fundamental science to enable determination of an accurate geoid model, allowing estimate of absolute surface geostrophic currents, which are necessary to quantify ocean's heat transport. The present geodetic satellites can measure sea level, its mass component and their changes, both of which are vital for understanding global climate change. Continuation of current satellite missions and the development of new geodetic technologies can be expected to further support accurate monitoring of the ocean. The Global Geodetic Observing System (GGOS) of the International Association of Geodesy (IAG) provides the means for integrating the geodetic techniques that monitor the Earth's time-variable surface geometry (including ocean, hydrologic, land, and ice surfaces), gravity field, and Earth rotation/orientation into a consistent system for measuring ocean surface topography, ocean currents, ocean mass and volume changes. This system depends on both globally coordinated ground-based networks of tracking stations as well as an uninterrupted series of satellite missions. GGOS works with the Group on Earth Observations (GEO), the Committee on Earth Observation Satellites (CEOS) and space agencies to ensure the availability of the necessary expertise and infrastructure. In this white paper, we summarize the community consensus of critical oceanographic observables currently enabled by geodetic systems, and the requirements to continue such measurements. Achieving this potential will depend on merging the remote sensing techniques with in situ measurements of key variables as an integral part of the Ocean Observing System.

\section{INTRODUCTION}

The guiding thesis of this white paper is that the tools of geodesy have the potential to transform the Ocean Observing System. Geodetic observations are unique in the way that they produce accurate, quantitative, and integrated observations of gravity, ocean circulation, sea surface height, ocean bottom pressure changes, and mass exchanges among the ocean, cryosphere, atmosphere and land. Specifically, we use continuously operating satellite altimetry and spaceborne gravity sensors to measure time series of sea surface slope and ocean bottom pressure variations and thus infer ocean circulation and mass distribution variations over a broad continuum of temporal and spatial scales. Achieving this potential will depend on merging the geodetic techniques with in situ measurements of key variables as an integral part of the Ocean Observing System.

The innovative capabilities of geodesy, as exemplified by the Global Geodetic Observing System (GGOS, Tab. 1 [46]) of the International Association of Geodesy (IAG), include the determination of the Earth's mean and time-dependent geometric shape, gravity field, rotation/orientation, and terrestrial reference frame. Combining the geometric methods with global gravity observables allows for the inference of mass anomalies, and mass transports within the Earth's system. The variations in Earth rotation and polar motion reflect both mass transports in the Earth system and the exchange of angular momentum among its components. The study areas of geodesy are therefore highly relevant to ocean observations, as they directly relate to ocean dynamics, and changes in ocean mass and sea level [4]. Changes in mass are directly related to water mass exchanges among the ocean, cryosphere, and hydrosphere [55]. GGOS provides the global terrestrial reference frame (in the form of the International Terrestrial Reference Frame, ITRF 2008 http://itrf.ensg.ign.fr), which is mandatory for most Earth observations. The accuracy and long-term stability of ITRF are crucial to many ocean observations, and in particular, critical to accurately measuring global sea level rise. 


\begin{tabular}{|l|l|l|l|}
\hline \multicolumn{1}{|c|}{ Component } & \multicolumn{1}{|c|}{ Objective } & \multicolumn{1}{c|}{ Techniques } \\
\hline $\begin{array}{l}\text { I. Geokinematics } \\
\text { (size, shape, } \\
\text { kinematics, } \\
\text { deformation) }\end{array}$ & $\begin{array}{l}\text { Shape and temporal variations of } \\
\text { land/ice/ocean surface (plates, intra- } \\
\text { plates, volcanoes, earthquakes, glaciers, } \\
\text { ocean variability, sea level) }\end{array}$ & $\begin{array}{l}\text { Altimetry, InSAR, GNSS- } \\
\text { cluster, VLBI, SLR, DORIS, } \\
\text { imaging techniques, levelling, } \\
\text { tide gauges }\end{array}$ & $\begin{array}{l}\text { International and national } \\
\text { projects, space missions, IGS, } \\
\text { future International Altimeter } \\
\text { Service, or InSAR service }\end{array}$ \\
\hline $\begin{array}{l}\text { II. Earth Rotation } \\
\text { (nutation, precession, } \\
\text { polar motion, } \\
\text { variations in length- } \\
\text { of-day) }\end{array}$ & $\begin{array}{l}\text { Integrated effect of changes in angular } \\
\text { momentum and moment of inertia } \\
\text { tensor (mass changes in atmosphere, } \\
\text { cryosphere, oceans, solid Earth, } \\
\text { core/mantle; momentum exchange } \\
\text { between Earth system components) }\end{array}$ & $\begin{array}{l}\text { Classical astronomy, VLBI, } \\
\text { LLR, SLR, GNSS, DORIS, } \\
\text { under development: terrestrial } \\
\text { gyroscopes }\end{array}$ & $\begin{array}{l}\text { International geodetic and } \\
\text { astronomical community (IERS, } \\
\text { IGS, IVS, ILRS, IDS) }\end{array}$ \\
\hline $\begin{array}{l}\text { III. Gravity field } \\
\text { Geoid, Earth's static gravitational } \\
\text { potential, temporal variations induced } \\
\text { by solid Earth processes and mass } \\
\text { transport in the global water cycle. }\end{array}$ & $\begin{array}{l}\text { Terrestrial gravimetry (absolute } \\
\text { and relative), airborne } \\
\text { gravimetry, satellite orbits, } \\
\text { dedicated satellite missions } \\
\text { (CHAMP, GRACE, GOCE) }\end{array}$ & $\begin{array}{l}\text { International geophysical and } \\
\text { geodetic community (GGP, IGFS, } \\
\text { and its associated IAG Services, } \\
\text { such as IGeS, BGI, etc.) }\end{array}$ \\
\hline IV. Terrestrial Frame & $\begin{array}{l}\text { Global cluster of fiducial points, } \\
\text { determined at mm to cm level }\end{array}$ & $\begin{array}{l}\text { VLBI, GNSS, SLR, LLR, } \\
\text { DORIS, time keeping/transfer, } \\
\text { absolute gravimetry, gravity } \\
\text { recording }\end{array}$ & $\begin{array}{l}\text { International geodetic community } \\
\text { (IERS with support of IDS, IGFS, } \\
\text { IGS, ILRS, and IVS) }\end{array}$ \\
\hline
\end{tabular}

Table 1: The Global Geodetic Observing System (GGOS). VLBI: Very Long Baseline Interferometry; SLR: Satellite Laser Ranging; LLR: Lunar Laser Ranging; GNSS: Global Navigation Satellite Systems; DORIS: Doppler Orbitography and Radio positioning Integrated by Satellite; InSAR: Interferometric Synthetic Aperture Radar; IGS: International GNSS Service; IAS: International Altimetry Service; IVS: International VLBI Service for Geodesy and Astrometry; ILRS: International Laser Ranging Service; IDS: International DORIS Service; IERS: International Earth Rotation and Reference Systems Service; IGFS: International Gravity Field Service; GGP: Global Geodynamics Project; BGI: International Gravimetric Bureau; IGeS: International Geoid Service. Modified from [46, Ch. 2]

The geodetic tools we discuss here relate primarily to altimetry and gravimetry (components 1 and 3 of Tab. 1). Satellite radar altimetry is an established technique for observing ocean surface height (or shape), its variability, and sea level change. For long-term ocean and climate studies (e.g. sea level rise), a series of TOPEX (Topography Experiment)/Jason-class repeat track radar altimetry satellite missions is a critical requirement. Data from non-repeat satellite altimetry missions have been used to generate a map of global ocean bathymetry with unprecedented accuracy and resolution, which can be applied to many areas of geophysics and oceanography, including ocean general circulation modelling. Satellite altimeter missions such as CryoSat-2 (Cryosphere Satellite) are important to the monitoring of the cryosphere and ice-covered oceans, and the planned Surface Water and Ocean Topography (SWOT) wide-swath synthetic aperture radar interferometry (InSAR) altimetry mission is intended for the mapping of high spatial resolution oceanic submesoscale variability and surface water hydrology.

Satellite gravimetry is complementary to satellite altimetry. A new generation of missions has been established, starting with the CHAllenging Minisatellite Payload for Geophysical Research (CHAMP, launched in 2000), the Gravity Recovery And Climate
Experiment (GRACE, 2002), and the Gravity field and steady state Ocean Circulation Explorer (GOCE, 2009) satellite missions. GOCE is designed to improve knowledge of the Earth's static gravity field and geoid, and will map the global geoid and gravity field with unprecedented accuracy $(1-2 \mathrm{~cm}$ in geoid, at $100 \mathrm{~km})$, as a reference for ocean circulation studies and sea level research. Accurate knowledge of the geoid combined with altimeter observations of sea surface height will enable quantification of general ocean circulation. GRACE is primarily aimed at observing the temporal gravity field caused by mass redistribution in the Earth system. These mass changes include the circulation of the atmosphere and ocean, changes in land hydrology, deglaciation, glacial isostatic adjustment, co-seismic and post-seismic earthquake deformations.

\section{MUCH BEAUTY IS SKIN DEEP: SEA SURFACE TOPOGRAPHY, CIRCULATION, AND SEA LEVEL RISE}

Satellite altimeters provide means for monitoring both short-and long-period temporal variations in sea surface height globally. The most important altimeters for sea level studies are those of TOPEX/Jason class that are not in Sun-synchronous orbits or alias signals associated with tides or the Sun into extremely long periods. These instruments provide sea surface height observations 
with accuracies of a few $\mathrm{cm}$, and they can be used to estimate the rate of global mean sea level rise to an accuracy of $0.3 \mathrm{~mm} /$ year [8] after extensive calibration efforts and comparison with independent observations. When altimeter data are compared and merged with in situ instrumentation provided by various coastal and offshore tide gauges (including GNSS (Global Navigation Satellite Systems)-equipped ocean buoys), they approach a coherent, worldwide monitoring system for sea level change [23]. The continuity of such a system, together with a number of complementary Earth observation systems, is clearly a community priority [61].

Satellite altimetry has significantly enhanced our knowledge of the ocean. For example, satellite altimetry has enabled the construction of global barotropic ocean tide models with $\mathrm{cm}$ accuracy in the deep ocean [14] and has demonstrated its potential to observe internal tides [50]. These observations have resulted in improved estimates of energy dissipated by tides throughout the deep ocean [39]. Radar altimetry has been used to observe evolutions in global mesoscale variabilities and ocean circulations throughout the ice-free ocean [64] and has been used to estimate changes in transports of the Antarctic Circumpolar Current [22].

The quasi-steady state of the surface geostrophic circulation is provided via the mean dynamic ocean topography (MDOT) determined from an altimetryderived mean sea surface (MSS) minus the geoid. The geoid is an equipotential surface and a unique reference from which to determine the absolute topography, compared with the relative topography that comes from in situ hydrographic profiles [63]. This means that the sea surface, as a level of known motion measured by altimetry, can be used to determine geostrophic currents at any depth, without requiring a velocity (or assumption of a velocity) at a subsurface level. Studies by [35] and [51] have demonstrated significant improvement of spatial resolution of the MDOT when in situ drifter data are added compared to the MDOT, which are based only on the GRACE-derived geoid and satellite altimetry data (Fig. 1). In turn, estimates of MDOT, based on drifters and hydrography greatly benefit from altimeter data, which reduces sampling error on small spatial scales, and the GRACE-derived geoid, which provides information at large scales. Earlier
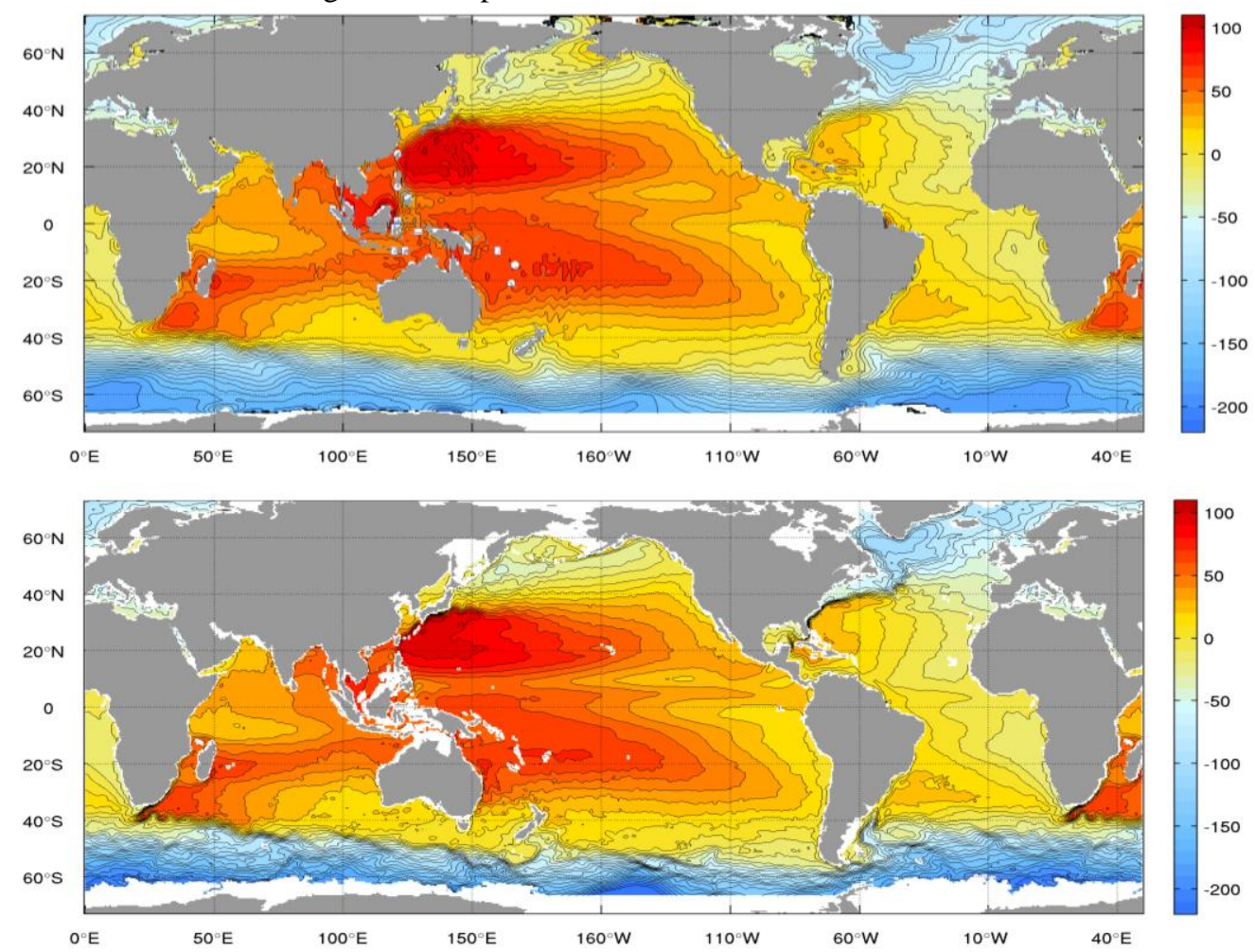

Figure 1. Maps of mean dynamic ocean topographies calculated for the period 1993-2002 from the GRACE gravity and satellite altimetry mean sea surface (top panel) and with added drifter-based technique of [35] (bottom panel). Contour interval is $10 \mathrm{~cm}$.

MDOT models, based only on drifters [41], were found to be biased in the Indian Ocean. This was due to an error in the correction for Ekman currents required to extract geostrophic currents from drifter trajectories [34]. Velocity observations, converted into the horizontal gradient of sea level, add the scales smaller 
than the ones resolved by the current model of the geoid, so that the combined products (Fig. 1b) better describe many complex current systems associated with sharp fronts. At present, the GRACE mean geoid model is accurate at 1-2 cm level at $200 \mathrm{~km}$ (half-wavelength). The anticipated geoid model from GOCE is expected to have a similar accuracy but at a much finer wavelength of $100 \mathrm{~km}$. Therefore, further improved accuracy of MDOT is expected in the near future [29].

The observation of the mesoscale and sub-mesoscale variability and geostrophic currents requires either an extensive constellation of nadir-pointing altimeters, or, optimally using at least one wide-swath instrument, such as the SWOT Mission [1], [15] and [16]. Such instrumentation is also required for the more complete exploitation of altimetry in coastal areas [11], and global surface water hydrology [1]. The observations of total land (including ice-sheets, mountain glaciers and ice caps) water storage change, or the absolute water storage exchange between the land/ice surface and the ocean, are critically important to quantify the freshwater budget and its effect on general ocean circulation and global sea level change [7], [30] and [36]. The cited studies address the former quantity, i.e. land storage change, which is demonstrated to be potentially quantifiable at the appropriate temporal and spatial resolutions by GRACE, satellite altimetry and hydrography data including Argo.

In coastal areas, which are often densely populated, geodetic techniques (e.g. tide gauges, GNSS, DORIS (Détermination d'Orbite et Radiopositionnement Intégrés par Satellite)) are crucial for monitoring changes in sea surface height and land surface height. Such observations provide critical constraints on models of the local, regional, and global processes that drive local sea level change. In the long term, these observations will be a crucial component of information required by decision and policy makers for mitigating and adapting to the coastal impact of climate change [47] caused by regional and global sea level rise [8].

\section{GETTING TO THE BOTTOM OF THINGS: OCEAN BOTTOM PRESSURE, INTERMEDIATE- DEPTH CIRCULATION, AND OCEAN HEAT STORAGE}

A basic tenet of measurement theory is to avoid wherever possible measuring a small signal as the difference of two large signals. Of the triad: sea level, density, ocean bottom pressure (OBP), the smallest signal is OBP [3], making it particularly attractive to monitor this quantity directly. Gradients of the ocean bottom pressure across major currents determine bottom geostrophic currents and can be used to infer variations in barotropic mass transport. In situ OBP sensors tend to have slowly varying datum fluctuations, which make determining long-term changes in transport difficult. Multi-year time series of OBP is difficult to obtain and most in situ measurements have typically been restricted to deployments of one year at a limited number of locations, although with present-day technology it is possible to deploy for 2 to 5 years; see e.g. [22], [37]. [44] and [62]. Consequently, long time series are only obtained by redeploying instruments at the same location. The combination of short time records for each instrument and their different drifts makes studying interannual and longer variability difficult or nearly impossible.

At present, GRACE measures the global time-variable gravity field with monthly sampling (or finer) and spatial scale as fine as $250 \mathrm{~km}$ or longer, depending on latitude and location. The ocean measurements have lower signal-to-noise ratios than the measurements over land or ice-sheets. GRACE has yielded monthly maps of mass changes since April 2002. These data can be used to infer time-variable ocean bottom pressure on similar time- and space-scales; see e.g. [26] and [55]. The accuracy of measurements yields suitable signal-tonoise ratios at mid to high latitudes [5], [12] and [38]. Because GRACE data are global, one can compute transport variability across a much larger area, and determine how the transport is changing from one area 

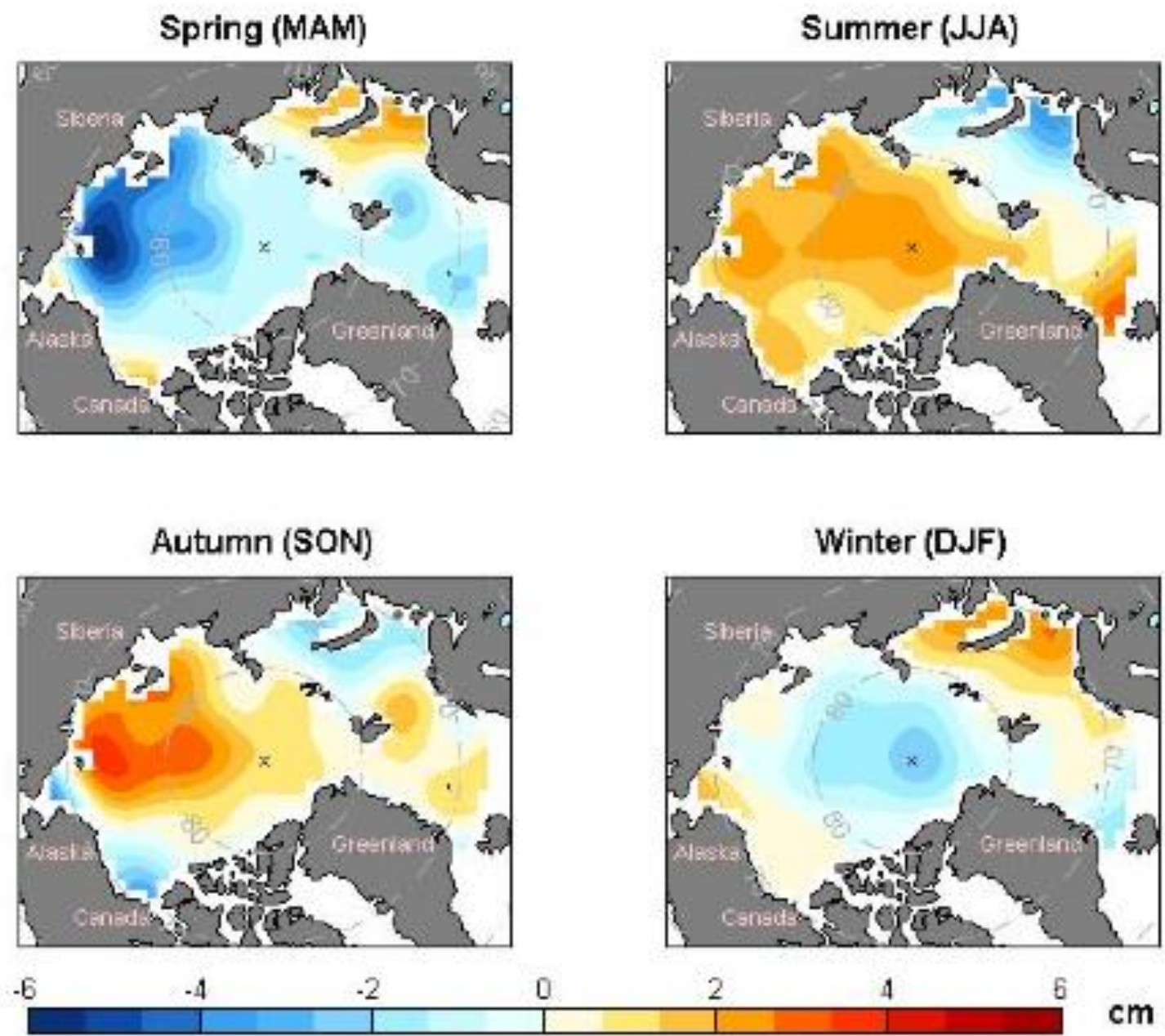

Figure 2. Seasonal averages of the monthly GRACE (Rel. 4, $300 \mathrm{~km}$ radius Gaussian filter) Arctic Ocean bottom pressure anomalies in cm water equivalent from August 2002 to May 2008, relative to the temporal mean from 2003 to 2006 [44].

to another, as [6] and [65] have done for the Antarctic Circumpolar Current. Because of the long, nearly continuous record, GRACE data have also been used to demonstrate significant low-frequency fluctuations in OBP: in the Arctic at seasonal [44] (Fig. 2) and interannual [38] time-scales in the North Pacific (Figs. 3 and 4) [53] and [10] that are likely related to transport changes and ENSO (El Niño/Southern Oscillation) events; and in the Southern Ocean [28] that dominate sea level change. However, the use of GRACE data to study changes in large-scale, lowfrequency volume transport has not yet been fully exploited The gradient of OBP fluctuations and the near bottom currents they produce are directly related to changes in sea surface elevation only in a barotropic flow, where pressure gradients are uniform with depth and directly relate to mass transport variations. However, the relationship is not so simple in a baroclinic environment, where changes in pressure gradients occur due to spatial differences in temperature and/or salinity, which vary with depth. In fact, model results suggest that at long time-scales OBP is strongly related to density variations that induce baroclinic currents [54] and [38] (Fig. 5). Thus to properly resolve fluctuations in the transports of mass, heat, and freshwater, one must combine GRACE with altimetric data and in situ measurements of $T$ and $S$ (Temperature and Salinity), from either hydrography or Argo floats.

Although the Argo program is now making global monthly observations of upper ocean temperature and salinity at a resolution of about $3^{\circ}$, combinations of satellite altimetry and GRACE data to estimate changes in steric sea level and heat storage (see e.g. [9] and [26]) may prove to be important. The Argo floats give accurate measures of the temperature and salinity profile for a particular location in the ocean. This will include both the long-wavelength signal as well as signals from very short-wavelength fluctuations, such as eddies. In some areas of the ocean (notably the western boundary currents and the Antarctic Circumpolar Current), small-scale, energetic eddies can obscure the 

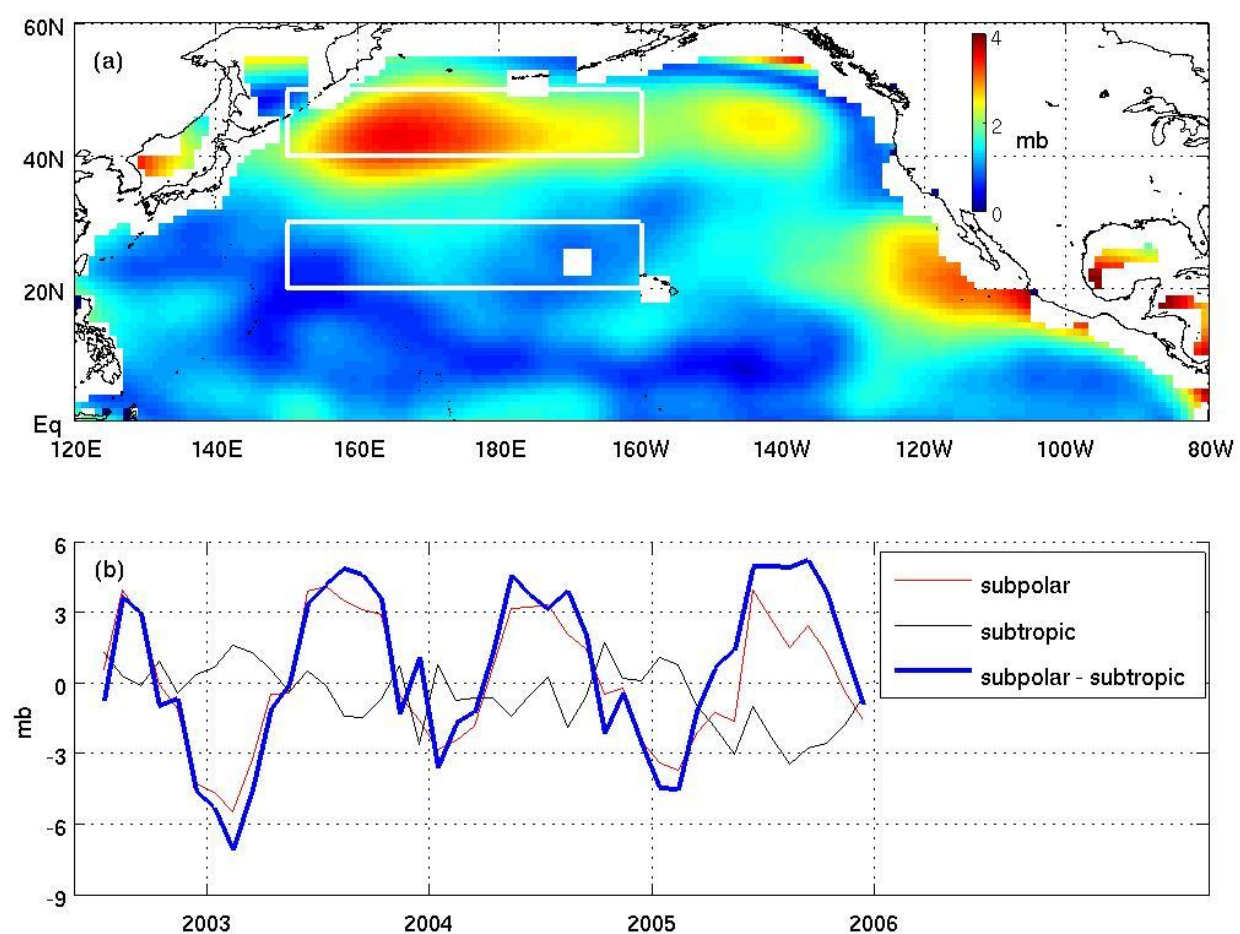

Figure 3. GRACE-observed Ocean-Bottom-Pressure oscillation in North Pacific is shown to link the tropical ENSO and the Aleutian Low through an atmospheric bridge [53].

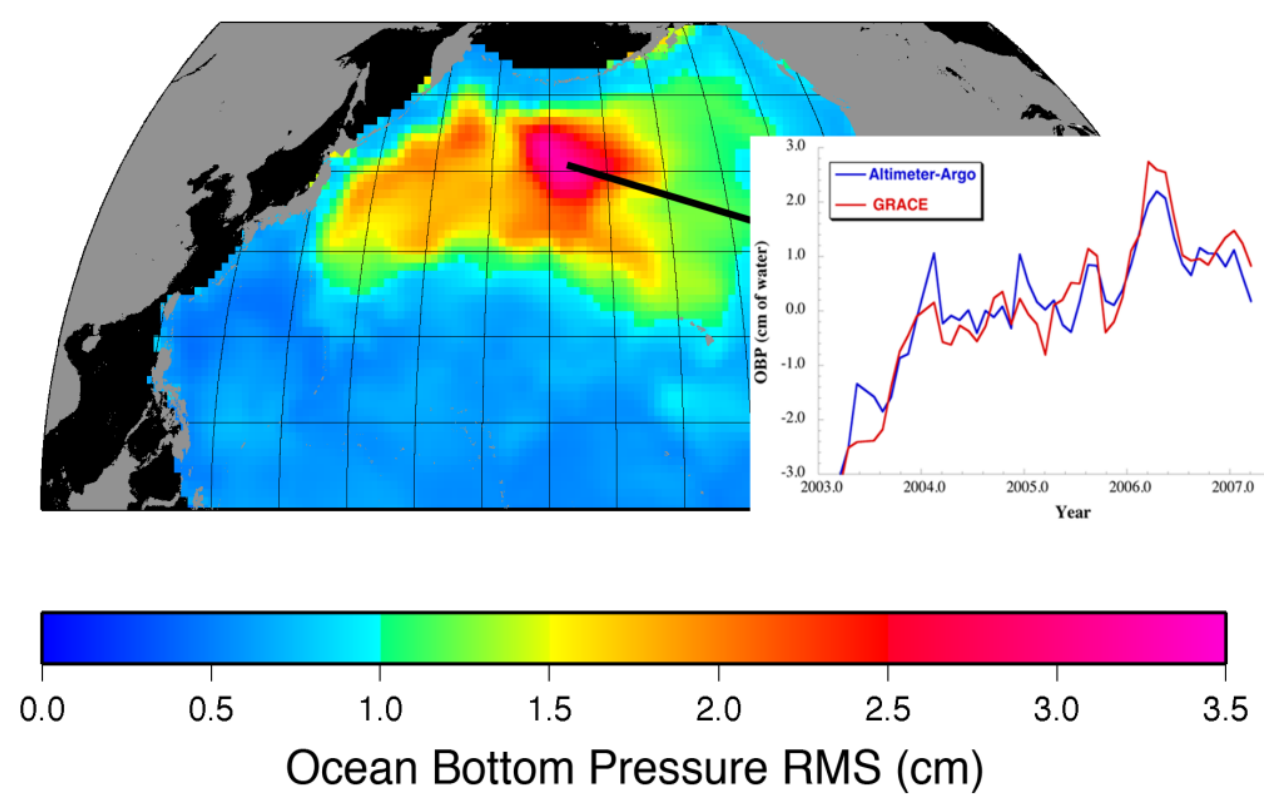

Figure 4. GRACE-observed ocean bottom pressure variations in North Pacific compared with steric-corrected (Argo) satellite altimetry [10]. 


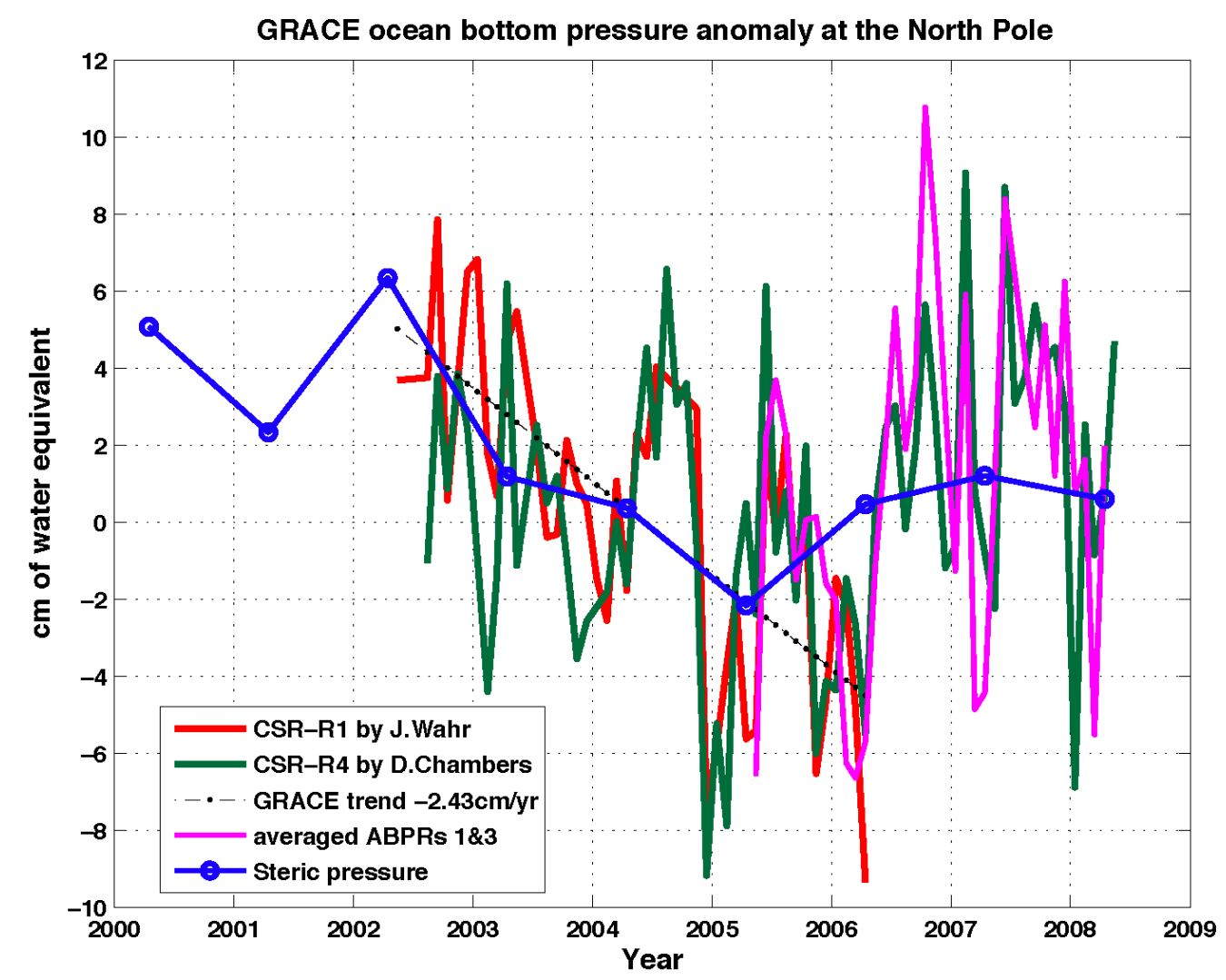

Figure 5. Bottom pressure at the North Pole from GRACE Releases 1 and 4 along with averages of in situ Arctic Bottom Pressure Recorder records. Absolute values are arbitrary and have been set to zero for Release 4. Other record averages are matched to Release 4. The interannual trends in steric pressure anomalies due to ocean mass changes from upper ocean hydrographic observations account for a significant part of the GRACE trends and in agreement with [38], [53] and [54]

longer wavelength signal. The distribution and number of floats will never be sufficient to fully reduce this type of aliasing.

Although the Argo program is now making global monthly observations of upper ocean temperature and salinity at a resolution of about $3^{\circ}$, combinations of satellite altimetry and GRACE data to estimate changes in steric sea level and heat storage (see e.g. [9] and [26]) may prove to be important. The Argo floats give accurate measures of the temperature and salinity profile for a particular location in the ocean. This will include both the long-wavelength signal as well as signals from very short-wavelength fluctuations, such as eddies. In some areas of the ocean (notably the western boundary currents and the Antarctic Circumpolar Current), small-scale, energetic eddies can obscure the longer wavelength signal. The distribution and number of floats will never be sufficient to fully reduce this type of aliasing.

More importantly, the combination of altimetry and GRACE should more accurately represent the longwavelength steric sea level. Thus, the altimetry-GRACE combination will be important as a fundamental reference to which information from the Argo floats can be added. In addition to the difference in horizontal resolution, there is a difference in vertical sampling. The current array of Argo floats only take measurements to a depth of 2,000 m, meaning there are several thousand meters of ocean depth not covered in many areas. The combination of GRACE and altimeter measurements, however, represents temporal changes in the vertical integral of density from the surface to the ocean floor. It may therefore be possible to detect changes in the deep ocean by combining all three data sets. While most seasonal to interannual fluctuations will be confined to the upper $1,000 \mathrm{~m}$ of the ocean, there is evidence that temperature fluctuations on periods of 10-years or more can occur in the deep ocean below 2,000 $\mathrm{m}$ [32]. Furthermore, sampling of the deep ocean has historically been inadequate [20] and there is currently no plan for comprehensive in situ sampling of the deep ocean. In addition, there are issues involving depth-dependent instrument biases in XBT (XBT (Expendable Bathythermograph) and MBT (Mechanical Bathythermograph) data and various investigators have different estimates of (upper) ocean warming and the 
corresponding thermosteric sea level rise. Estimates of thermal expansion of the upper ocean vary for the last 50 years from $0.24 \mathrm{~mm} / \mathrm{yr}$ to $0.6 \mathrm{~mm} / \mathrm{yr}$ [2], [13], [20] [25] and [56].

Separating the globally averaged sea level rise into its two key components, water mass addition and density changes, allows for a comparison of the global water budget with estimates of ice melt from glaciers and ice sheets. This is a very difficult computation, which is complicated by the correlation of the spatial and temporal characteristics of some of the contributions. It requires extreme accuracy [7], [31], [33], [43], [45] and [57], and current estimates disagree at the $\sim 1 \mathrm{~mm} / \mathrm{yr}$ level. However, much of this is related to the glacial isostatic adjustment (GIA) forward models that are used as correction to the GRACE data and the short time series available for the study. These GIA models, expressed in terms of oceanic mass variations, have an averaged signal of 1-2 $\mathrm{mm} / \mathrm{yr}$ over the ocean, indicating significant discrepancy depending on the choice of the model. In addition, the models also predicted a correction on the same magnitude as the observed GRACE ocean mass signals. With longer time series and other geodetic measurements, there is potential to improve GIA models. Also, since GIA corrections are quite large for GRACE but not for altimetry, long timeseries of altimetry, GRACE, and Argo can be used to evaluate different GIA models. Here again, the combination of GRACE, altimetry and Argo floats is a novel approach to provide an improved quantification of the state of the ocean. Moreover, geodetic observations (including GRACE, gravimetry, laser and radar altimetry, and InSAR and Wide-Swath altimeters) also provide the means to determine mass changes in the ice sheets, glaciers and land water storage and discharge. In fact, the geodetic techniques are crucial in establishing a global mass balance in the water cycle as an additional constraint for changes in the ocean mass.

Geostrophic ocean currents reflect a balance between pressure gradients and the Coriolis force. While surface geostrophic currents, which have both baroclinic and barotropic components, are defined by the dynamic surface topography, below the sea surface. The baroclinic component due to horizontal density gradients tends to diminish the currents and turn their direction with depth. Combining the recently available high-quality MDOT with satellite altimetry and CTDprofiles from more than 3,000 Argo floats now allows one to derive the absolute dynamic height (ADH) and assess geostrophic currents in the upper 2,000 meters of the ocean. This is an idea first proposed nearly 30 years ago [63], demonstrated during the World Ocean Circulation Experiment (WOCE) using hydrographic data [17], and that is now possible in part due to the innovative geodetic satellite missions and techniques, in particular from the contribution of GOCE to the improved quantification of the absolute general ocean circulation [29]. Recently, a preliminary monthly gridded dataset was made available at the Asia-Pacific Data Research Center (APDRC). Of particular interest are the studies of the vertical structure of baroclinic currents [57] and [58].

\section{EMERGING GEODETIC TECHNOLOGY \& CHALLENGE SATELLITE ALTIMETRY:}

Because of its enormous value for ocean monitoring, altimetry will become part of operational satellite systems such as the Jason series and the Sentinel series of European Union/European Space Agency (EU/ESA) Global Monitoring for Environment and Security (GMES) [60]. Significant new technology developments include the Delay/Doppler altimeter [50] with an earlier version of the instrument design, the SAR/Interferometric Radar Altimeter (SIRAL) system onboard of the CryoSat mission, and the wide-swath InSAR radar altimetry instrument, onboard of SWOT. An emerging technique is GNSS reflectrometry, i.e. the analysis of the travel time of signals emitted by GNSS satellites, reflected at the ocean surface and received in airplanes or low orbiting satellites. A number of groups are currently investigating the accuracy of such a measurement concept. First results look promising but the technique is far from being well established.

Satellite gravimetry: GRACE is currently providing very accurate monthly time series of changes in the Earth's wavelength gravity field. This adds a new - and very central - parameter set to the study of global change phenomena such as de-glaciation in the large ice shields of Antarctica and Greenland, sea level rise, or the variations of the global water cycle. GOCE will deliver a global static gravity field and geoid with unprecedented accuracy and spatial resolution. It will in particular serve as reference for global ocean circulation studies by altimetry.

To completely understand the physical processes of the Earth under a warming climate, continuous measurements of gravity changes in the form of an ongoing series of satellites are necessary. Workshops on the future satellite gravimetry missions were held at ESA/ESTEC (European Space Research and Technology Centre) [27], and at the Technische Universität Graz in 2007 and 2009, respectively. To facilitate a long-term commitment to satellite gravity missions, the 2009 Graz workshop (http://www.igcp565.org/workshops/Graz.) was coorganized by IAG/GGOS and Global Earth Observation (GEO) in cooperation with Space Agencies to formulate and agree on a roadmap for future gravity satellite missions. The Workshop participants agreed on a roadmap for future gravity satellite missions. The strategic target for this roadmap is to accomplish "a 
multi-decade, continuous series of space-based observations of changes in the Earth's gravity field begun with the GRACE mission, and leading, before 2020, to satellite systems capable of monitoring temporal gravity field from global down to regional spatial scales and on time scales of two weeks or shorter. This data set will contribute to an integrated and sustained operational observing system for mass redistribution, to monitor natural hazards and their potential early detection, to support global water resource management, and to improve understanding of climate change."

In addition, the Graz Workshop participants supported the idea of a GRACE stopgap or continuity mission based on the present GRACE technology, with emphasis on the continuation of time series of global gravity changes with a minimum gap. Current estimate for the end of the GRACE mission is 2013, requiring a high priority GRACE Continuity satellite mission launch soon after that time, e.g. 2015. The U.S. NRC Decadal Survey lists the GRACE follow-on (laser interferometry) as one of its recommended missions for the next 15 years, but in the 2017-2020 time frame. This would mean a gap of 5-8 years in time variable gravity and OBP, with unacceptable negative impacts on all scientific objectives and applications described above. If this delay occurs, we will have to rely on optimum use of a greatly expanded program of in situ observations.

The medium term priority should be focused on higher precision and higher resolution gravity in both space and time. This step requires (1) the reduction of the current level of aliasing of high-frequency geophysical signals including ocean tides and atmosphere loading into the gravity field time series (2) the mitigation of geographically-correlated high spatial frequency distortions (caused primarily by the peculiar nonisotropic sensitivity of a single pair of low-low SST (Satellite to Satellite Tracking) measurement system and (3) the improvement of the separability of the observed geophysical signals. Elements of a strategy in this direction are the use of two or more pairs of satellites, probably with one pair in a moderate inclination orbit, and efforts to improve the background models, for example, perturbations on the satellites due to atmosphere loading and ocean tides. This will open the door to an efficient use of improved sensor systems, such as laser interferometry ranging systems and active angular and drag-free control systems. Other experimental and longer-term sensor technologies that potentially shows promise for gravity observations include cold-atom quantum gravity sensors and ultrastable clocks. The various geodetic techniques and their maturity level and future challenges are summarized in Tab. 2.

\begin{tabular}{|l|l|l|}
\hline \multicolumn{1}{|c|}{ Technique } & \multicolumn{1}{c|}{ Maturity } & \multicolumn{1}{c|}{ Challenges } \\
\hline Satellite radar altimetry & Established & cm-orbits, ionosphere, EM bias \\
\hline GRACE Continuity & Established & De-aliasing, improvement of background models \\
\hline Wide-swath altimetry & New Technology & Processing of InSAR altimetry data, EM bias \\
\hline GRACE Follow-on & New Technology & Laser link, drag-free, de-aliasing \\
\hline GNSS reflectometry & Experimental & Processing of reflected signals, receivers, antennae \\
\hline
\end{tabular}

Table 2: New geodetic satellite techniques for oceanography

\section{PROPOSAL FOR INTEGRATION OF GGOS INTO THE OCEAN OBSERVING SYSTEM}

Historically, oceanography has suffered from observations that are too sparse in space and time to give a clear picture of the ocean environment. We feel the new remote sensing tools of geodesy, when combined intelligently with in situ measurements of the Ocean Observing System, have the potential to make a transformative leap in the breadth and detail of our observations. With these tools, we can potentially measure deflection of the sea surface and ocean bottom pressure to infer circulation and mass distribution over a broad continuum of temporal and spatial scales. Furthermore, these same satellite tools provide observables of the cryospheric, hydrologic and geodynamic mass changes of the Earth with a global perspective that no other observational systems could provide.

Utilizing the full potential of the geodetic technologies requires integration of altimetry and gravimetry, and this is one of the key objectives of GGOS. GGOS plays an important role in bringing the global geodetic activities into the ocean observing system. GGOS represents IAG as Participating Organization in GEO and other international activities [46], and these links can be explored to raise awareness of the geodetic contribution and make the geodetic observations and products available to the ocean observation community. An example illustrating this contribution of the geodetic ocean observing system could be the monitoring of the Atlantic Meridional Overturning Circulation (AMOC) to study its potential weakening as a result of anthropogenic climate change. Here multi-mission radar altimetry sea level and surface 
geostrophic current velocities, GRACE-derived ocean bottom pressure and GRACE-observed land and ice melt water mass fluxes, GOCE-measured geoid and MODT, mooring arrays, and data from tide gauges and Argo, collectively can establish a monitoring system to potentially monitor the present-day evolution of the AMOC. Another scientific application is to estimate strait and inter-ocean transport using the combined altimetry sea surface height and GRACE ocean bottom pressure data [48] and [53]. These applications are of fundamental interest to address research problems in oceanography [18] and climate change [19] and [21]. The improvement and the constraints of the GIA processes resulting from the Last Glacial Maximum and to a lesser extent, the Little Ice Age, have significant impact on accurate estimates of oceanic mass variation. It is recommended that the GIA forward models be improved and their error characteristics be quantified when they are used to correct GIA effects integrated (geodetic and in situ) measurements to quantify oceanic mass variations and global water cycles and their impact on ocean freshening and circulation.

There are serious challenges to be sure. The GRACE measurements have demonstrated its importance for ocean monitoring. Now the gap between GRACE and the GRACE follow-on is seen as a critical problem. GRACE has a nominal mission life span of 5 years (2002-2007), however, its extraordinary performance provides an opportunity to extend its mission to 2013. The GRACE follow-on mission is expected to be launched in the 2017-2020 time frame. There is a reasonable good chance that a GRACE Continuity mission to minimize the data gap between GRACE and its follow-on would be launched around 2015. It is recommended that the planned GRACE Continuity mission would have potential incremental improvements such as mitigation of temporal and spatial aliasing and improvement of spatial resolutions by flying more than one pairs of GRACE-type satellites in a constellation, at distinct inclinations and at lower altitudes.

Much of the progress in ocean observation ultimately will depend on the success of the global geodetic community behind GGOS to maintain the accurate and long-term reference frame required for Earth observation. Continued refinements to the terrestrial reference frame depend on adequate coverage and collocation of geodetic techniques, including VLBI and satellite laser ranging. Closing the current large geographical gaps in the global network of core geodetic stations is therefore a high priority of GGOS, as is the identification and maintenance of the core geodetic infrastructure required for the determination of an ITRF that meets the requirements of global change research, including those of oceanography [46, Chapter 11]. The accuracy and stability of the ITRF, for example, have significant impacts on monitoring sea level change and are therefore affecting the determination of the absolute ocean circulation. It is recommended that the drift of the ITRF be monitored to be $<0.1 \mathrm{~mm} / \mathrm{yr}$. Finally, future satellite altimeters should be designed to meet at least the $0.3 \mathrm{~mm} / \mathrm{yr}$ accuracy in global sea level needed for climate studies that is currently achieved by extensive post-flight calibration that takes months or sometimes years [8].

There are key in situ measurements that we will particularly value as part of the ocean observing system. These include: (1) independent observations of sea surface height (i.e. tide gauges, most equipped with GNSS receivers), that can validate and extend the satellite altimeter results (2) hydrography (e.g. Argo floats) that would extend the coverage and sampling to deep ocean $(>2,000 \mathrm{~m})$ and that validates and details the mass distribution changes inferred from satellite altimetry and gravity (3) in situ bottom pressure arrays, including those in the polar ocean, that validates the satellite gravity-based measurements and could improve our ability to de-alias the satellite gravity and altimetry data for tidal and other high frequency motions and (4) Lagrangian drifter measurements with which to compare velocity solutions over broad areas. It is recommended that the Argo arrays be enhanced to cover the commensurate observational sampling in the deeper part of the ocean $(>2,000 \mathrm{~m})$.

Perhaps one of the most important outcomes of this white paper and OceanObs'09 would be the thorough integration of geodesy into the ocean observing system of the future. The ocean science community is on the verge of putting together a larger and ever improving array of observations. If geodetic techniques are an integral part of the observing system, the tools of geodesy can provide unprecedented spatial and temporal continuity to the physical observations and consequent insights into the behaviour of the world ocean.

\section{ACKNOWLEDGEMENT}

We thank Carl Wunsch for his constructive comments, which have improved this manuscript. Peter H. Luk's help on text-processing of the manuscript is gratefully acknowledged.

\section{REFERENCES}

[1] Alsdorf, D., Rodriguez, E, \& Lettenmaier, D. (2007) Measuring surface water from space, Rev. Geophys., 45, doi:10.1029/2006RG000197, 2007. 
[2] Antonov, J., S. Levitus, S. \& Boyer, T. (2005). Steric variability of the world ocean, 1955-2003, Geophys. Res. Lett., 32(12), L12602,

doi:10.1029/2005GL023112.

[3] Bingham, R. J. \& Hughes, C. W. (2008). The relationship between sea-level and bottom pressure variability in an eddy-permitting ocean model. Geophys. Res. Lett., 35, L03602, doi:10.1029/2007GL032662.

[4] Blewitt, G., Altamimi, Z. Davis, J. Gross, R. Kuo, C. Lemoine, F. Neilan, R. Plag, H.P. Rothacher, M. Shum, C. Sideris, M. Schoene, T. Tregoning, P. \& Zerbini, S. (2006). Geodetic observations and global reference frame contributions to understanding sea level rise and variability, in Understanding Sea-level Rise and Variability, A World Climate Research Programme Workshop and a WCRP contribution to the Global Earth Observation System of Systems, 6-9 June 2006, UNESCO, Paris, T. Aarup, J. Church, S. Wilson, \& P. Woodworth (Ed.), 127-143, WCRP, World Meterological Organization, Paris.

[5] Böning, C., Timmermann, R. Macrander, A. \& Schröter, J. (2008). A pattern-filtering method for the determination of ocean bottom pressure anomalies from GRACE solutions, Geophys. Res. Lett., 35, L18611, doi:10.1029/2008GL034974.

[6] Böning, C., Timmermann, R. Danilov, D. \& Schröter, J. (2009). On the representation of transport variability of the Antarctic Circumpolar Current in GRACE gravity solutions and numerical ocean model simulations, In Flechtner F, Gruber T, Güntner A, Mandea M, Rothacher M, Schöne T, Wickert J (eds.) Satellite Geodesy and Earth System Science, Springer-Verlag, Berlin, Heidelberg.

[7] Cazenave, A., Dominh, K. Guinehut, S, Berthier, E. Llovel, W, Ramillien, R, Ablain, M. \& Larnicolm, G. (2009). Sea level budget over 2003-2008: A reevaluation from GRACE space gravimetry, satellite altimetry and Argo, Global and Planetary Change, 65, 83-88, doi:10.1016/j.gloplacha.2008.10.004.

[8] Cazenave, A. \& Co-Authors (2010). "Sea Level Rise Regional and Global Trends" in these proceedings (Vol. 1), doi:10.5270/OceanObs09.pp.11.

[9] Chambers, D.P., Cipollini, P. Fu, L.L. Hurell, J.W. Merrifield, M. Nerem, R.S. Plag, H.P. Shum, C.K. Willis, J. \& Chambers, D.P. (2006). Observing seasonal steric sea level variations with GRACE and satellite altimetry, J. Geophys. Res., 111 (C3), C03010, doi:10.1029/2005JC002914.

[10] Chambers D.P. \& Willis J.K. (2008). Analysis of largescale ocean bottom pressure variability in the North Pacific, J. Geophys. Res., 113, C11003, doi:10.1029/2008JC004930.

[11] Cipollini, P. \& Co-Authors (2010). "The Role of Altimetry in Coastal Observing Systems" in these proceedings (Vol. 2), doi:10.5270/OceanObs09.cwp.16.
[12] Dobslaw, H., \& Thomas, M. (2007). Simulation and observation of global ocean mass anomalies, $J$. Geophys. Res., 112, C05040, doi:10.1029/2006JC004035.

[13] Domingues, C., Church, J. White, N. Gleckler, P. Wijffels, S. Barker, P. \& Dunn, J. (2008). Improved estimates of upper-ocean warming and multi-decadal sea-level rise, Nature, 453, doi:10.1038/nature07080.

[14] Fu, L.L. \& Cazenave, A. (2000). Satellite altimetry and Earth sciences: a handbook of techniques and applications, Academic Press, San Diego, CA.

[15] Fu, L.L. (2007). Objectives and requirements of SWOT for observing the oceanic mesoscale variability, NASA SWOT Workshop, Scripps Institute of Oceanography, April 28-May 1.

[16] Fu, L. \& Co-Authors (2010). "The Surface Water and Ocean Topography (SWOT) Mission" in these proceedings (Vol. 2), doi:10.5270/OceanObs09.cwp.33.

[17] Ganachaud, A., \& Wunsch, C. (2000). Improved estimates of global ocean circulation, heat transport and mixing from hydrographic data, Nature, 408 , 453-457.

[18] Godfrey, J.S. (1996). The effect of the Indonesian throughflow on ocean circulation and heat exchange with the atmosphere: A review, J. Geophy. Res., 101, 12217-12237.

[19] Gordon, A.L., Susanto, R.D. \& Vranes, K. (2003). Cool Indonesian Throughflow as a consequence of restricted surface layer flow, Nature, 425, 824-828.

[20] Gouretski, V., \& Koltermann, K.P. (2007). How much is the ocean really warming? Geophys. Res. Lett., 34: L01610, doi:10.1029/2006GL027834.

[21] Hansen, B., Turrell, W.R. \& Osterhus, S. (2001). Decreasing overflow from the Nordic seas into the Atlantic Ocean through the Faroe Bank channel since 1950, Nature, 411, 927-930.

[22] Hughes, C.W., Woodworth, P.L. Meredith, M.P. Stepanov, V. Whitworth, T. \& Pyne, A.R. (2003). Coherence of Antarctic sea levels, Southern Hemisphere Annular Mode, and flow through Drake Passage. Geophys. Res. Lett, 30(9), 1464, doi:10.1029/2003GL017240.

[23] IOC, Global Sea Level Observing System Implementation Plan 2009, (edited by M. Merrifield). Intergovernmental Oceanographic Commission, in preparation.

[25] Ishii, M., \& Kimoto, M. (2009). Reevaluation of historical ocean heat content variations with timevarying XBT and MBT depth bias corrections, $J$. Oceanography, 65, 287-299.

[26] Jayne, S. R. (2006), Circulation of the North Atlantic Ocean from altimetry and the Gravity Recovery and Climate Experiment geoid, J. Geophys. Res., 111, C03005, doi:10.1029/2005JC003128. 
[27] Koop, R., \& Rummel, R. (2007). The future of satellite gravimetry, Workshop on the Future of Satellite Gravimery Report, ESTEC, Noordwijk, The Netherlands, April 12-13.

[28] Kuo, C., Shum, C. Guo, J. Yi, Y. Braun, A. Fukumori, I. Matsumoto, K. Sato, T. \& Shibuya, K. (2008). Southern Ocean Mass Variation Studies Using GRACE and Satellite Altimetry, Earth Planets and Space, 60, 1-9.

[29] Legrand, P. (2005). Future Gravity Missions and Quasi-steady Ocean Circulation, Earth, Moon, and Planets, 94(1-22), doi:10.1007/s11038-004-7606-9.

[30] Lettenmaier D. \& Milly, C. (2009). Land waters and sea level, Nature, 2, 452-454.

[31] Leuliette, E.W., \& Miller, L. (2009). Closing the sea level rise budget with altimetry, Argo, and GRACE, Geophys. Res. Lett., 36, L04608, doi:10.1029/2008GL036010.

[32] Levitus, S., Antonov, J. \& Boyer, T. (2005). Warming of the world ocean, 1955-2003. Geophys. Res. Lett., 32: L12602, doi:10.1029/2005GL023112.

[33] Lombard, A., Garcia, D. Ramillien, G. Cazenave, A. Biancale, R. Lemoine, J.M. Flechtner, F. Schmidt, R. \& Ishii, M. (2007). Estimation of steric sea level variations from combined GRACE and Jason-1 data, Earth and Planetary Science Letters, 254, 194-202, doi:10.1016/j.epsl.2006.11.035.

[34] Maximenko, N.A., \& Niiler, P.P. (2005). Hybrid decade-mean global sea level with mesoscale resolution. In Saxena, N. (Ed.) Recent Advances in Marine Science and Technology, 2004. Honolulu: PACON International, 55-59.

[35] Maximenko, N., Niiler, P. Rio, M.H. Melnichenko, O. Centurioni, L. Chambers, D. Zlotnicki, V. \& Galperin, B. (2009). Mean dynamic topography of the ocean derived from satellite and drifting buoy data using three different techniques. J. Atmos. Oceanic Tech., 26(9), 1910-1919.

[36] Milly, P.C.D., Cazenave, A. Famiglietti, J. Gornitz, V. Laval, K. Lettenmaier, D. Sahagian, D. Wahr, J. \& Wilson, C. (2009). Terrestrial water storage contributions to sea level rise and variability, Proceedings of the WCRP workshop 'Understanding sea level rise and variability', eds. J. Church, P. Woodworth, T. Aarup and S. Wilson et al., Blackwell Publishing, Inc.

[37] Morison, J.H. (1990). Seasonal fluctuations in the West Spitsbergen Current estimated from bottom pressure measurements. J. Geophys. Res., 96 (C10), 18,38118,395 .

[38] Morison, J., Wahr, J. Kwok, R. \& Peralta-Ferriz, C. (2007). Recent trends in Arctic Ocean mass redistribution revealed by GRACE, Geophys. Res. Lett., 34, L07602, doi:10.1029/2006GL029016.

[39] Munk, W.H. (1997). Once again: Once again - tidal friction, Progress in Oceanography, 40, 1-4, 7-35.
[40] Nerem, R. \& Co-Authors (2010). "Observations of Sea Level Change: What Have We Learned and What Are the Remaining Challenges?" in these proceedings (Vol. 2), doi:10.5270/OceanObs09.cwp.65.

[41] Niiler, P.P., Maximenko, N.A., \& McWilliams, J.C. (2003). Dynamically balanced absolute sea level of the global ocean derived from near-surface velocity observations, Geophys. Res. Lett., 39(22), 2164, doi:10.1029/2003GL018628.

[42] Park, J.-H. Watts, D.R. Donohue, K.A. \& Jayne, S.R. (2008). A comparison of in situ bottom pressure array measurements with GRACE estimates in the Kuroshio Extension, Geophys. Res. Lett., 35, L17601, doi:10.1029/2008GL034778.

[43] Peltier. W.R. (2009). Closure of the budget of global sea level rise over the GRACE era: the importance and magnitudes of the required corrections for global glacial isostatic adjustment Quaternary Science Reviews, Volume 28, Issues 17-18, , Pages 16581674, Quaternary Ice Sheet-Ocean Interactions and Landscape Responses, doi:10.1016/j.quascirev.2009.04.004

[44] Peralta-Ferriz, C., J. Morison, J. Wahr, and R. Kwok, 2007, Variability of Mass in the Arctic Ocean Using GRACE and In Situ Bottom Pressure Measurements, Eos Transactions. AGU, 88(52), Fall Meet. Suppl., Abstract U21C-0624.

[45] Plag, H.P. (2006). Recent relative sea level trends: an attempt to quantify the forcing factors, Phil. Trans. Roy. Soc. London, A, 364, 1841-1869.

[46] Plag, H.P. \& Pearlman, M. eds. (2009). The Global Geodetic Observing System: Meeting the Requirements of a Global Society on a Changing Planet in 2020, Geoscience Books, Springer, Berlin, $332 \mathrm{pp}$.

[47] Plag, H.P. \& Co-Authors (2010). "Observations as Decision Support for Coastal Management in Response to Local Sea Level Changes" in these proceedings (Vol. 2), doi:10.5270/OceanObs09.cwp.69.

[48] Qu, T., and Y. T. Song (2009), Mindoro Strait and Sibutu Passage transports estimated from satellite data, Geophys. Res. Lett., 36, L09601, doi:10.1029/2009GL037314.

[49] Raney, R. (1998). The delay/Doppler radar altimeter, IEEE Trans. Geosci. 472, Remote Sens., 36(5), 15781588.

[50] Ray, R., \& Mitchum, G. (1996). Surface manifestation of internal tides generated near Hawaii, Geophys. Res. Lett., 23(16), 2101-2104.

[51] Rio M., \& Hernandez, F. (2004). A mean dynamic topography computed over the world ocean from altimetry, in situ measurements, and a geoid model, $J$. Geophys. Res., 109, C12032, doi:10.1029/2003JC002226. 
[52] Song, Y.T. (2009). Estimation of interbasin transport using ocean bottom pressure: Theory and model for Asian marginal seas, J. Geophys. Res., 111, C11S19, doi:10.1029/2005JC003189.

[53] Song, Y.T. \& Zlotnicki, V. (2008). The subpolar oceanbottom-pressure oscillation and its links to ENSO, Int. J. Remote Sensing, Vol. 29 (21), 6091-6107.

[54] Vinogradova, N., Ponte, R. \& Stammer, D. (2007). Relation between sea level and bottom pressure and the vertical dependence of oceanic variability, Geophys. Res. Lett., 34, L03608, doi:10.1029/2006GL028588.

[55] Wahr, J., Molenaar, M. \& Bryan, F. (1998). Timevariability of the Earth's gravity field: Hydrological and oceanic effects and their possible detection using GRACE, J. Geophys. Res., 103, 32,205-30,229.

[56] Wijffels, S.E., Willis, J. Domingues, C.M. Barker, P. White, N.J. Gronell, A. Ridgway, K. \& Church, J.A. (2008). Changing expendable bathythermograph fall rates and their impact on estimates of thermosteric sea level rise, J. Climate, 21, 5657-5672.

[57] Willis, J.K., \& Fu, L.L. (2008). Combining altimeter and subsurface float data to estimate the timeaveraged circulation in the upper ocean. J. Geophys. Res., 113, C1207, doi:10.1029/2007JC004690.

[58] Willis, J.K., Roemmich, D. \& Cornuelle, B. (2003). Combining altimetric height with broadscale profile data to estimate steric height, heat storage, subsurface temperature, and sea-surface temperature variability. J. Geophys. Res., 108(C9), 3292, doi:10.1029/2002JC001755.

[59] Willis, J.K., Chambers, D.P. \& Nerem, R.S. (2008). Assessing the globally averaged sea level budget on seasonal to interannual timescales, J. Geophys. Res., 113, C06015, doi:10.1029/2007JC004517.

[60] Wilson, S., \& Parisot, F. (2008). Proc. CEOS Ocean Surface Topography Constellation Strategic Workshop, Assmannshausen, Germany, 29-31 January.

[61] Wilson, S., W, Abdalti, D. Alsdorf, J. Benveniste, H. Bonekamp, G. Cogley, M. Drinkwater, L.-L. Fu, R. Gross, B. Haines, E. Harrison, G. Johnson, M. Johnson, J. LaBrecque, E. Lindstrom, M. Merrifield, L. Miller, E. Pavlis, S. Piotrowicz, D. Roemmich, D. Stammer, R. Thomas, E. Thouvenot, and P. Woodworth (2010), "Observing Systems Needed to Address Sea-level Rise and Variability", Blackwells Pub., Eds. J. A. Church, P. L. Woodworth, T. Aarup and W. S. Wilson, London, doi:10.1007/s11625-0080042-4.

[62] Woodworth, P.L., Vassie, J.M. Hughes, C.W. \& Meredith, M.P. (1996). A test of the ability of TOPEX/POSEIDON to monitor flows through the Drake Passage, J. Geophys. Res., 101(C5), 1193511947.
[63] Wunsch, C., \& Gaposchkin, E.M. (1980). On using satellite altimetry to determine the general circulation of the ocean with application to geoid improvement, Rev. Geophys., 18, 725-745.

[64] Wunsch, C., Ponte, R.M. \& Heimbach, P. (2007). Decadal trends in sea level patterns: 1993-2004, J. Climate, 20(24), 5889-5911.

[65] Zlotnicki, V., Wahr, J. Fukumori, I. \& Song, Y.T. (2007). Antarctic circumpolar current transport variability during 2003-05 from GRACE, J. Phys. Ocean., 37, 230-244. 